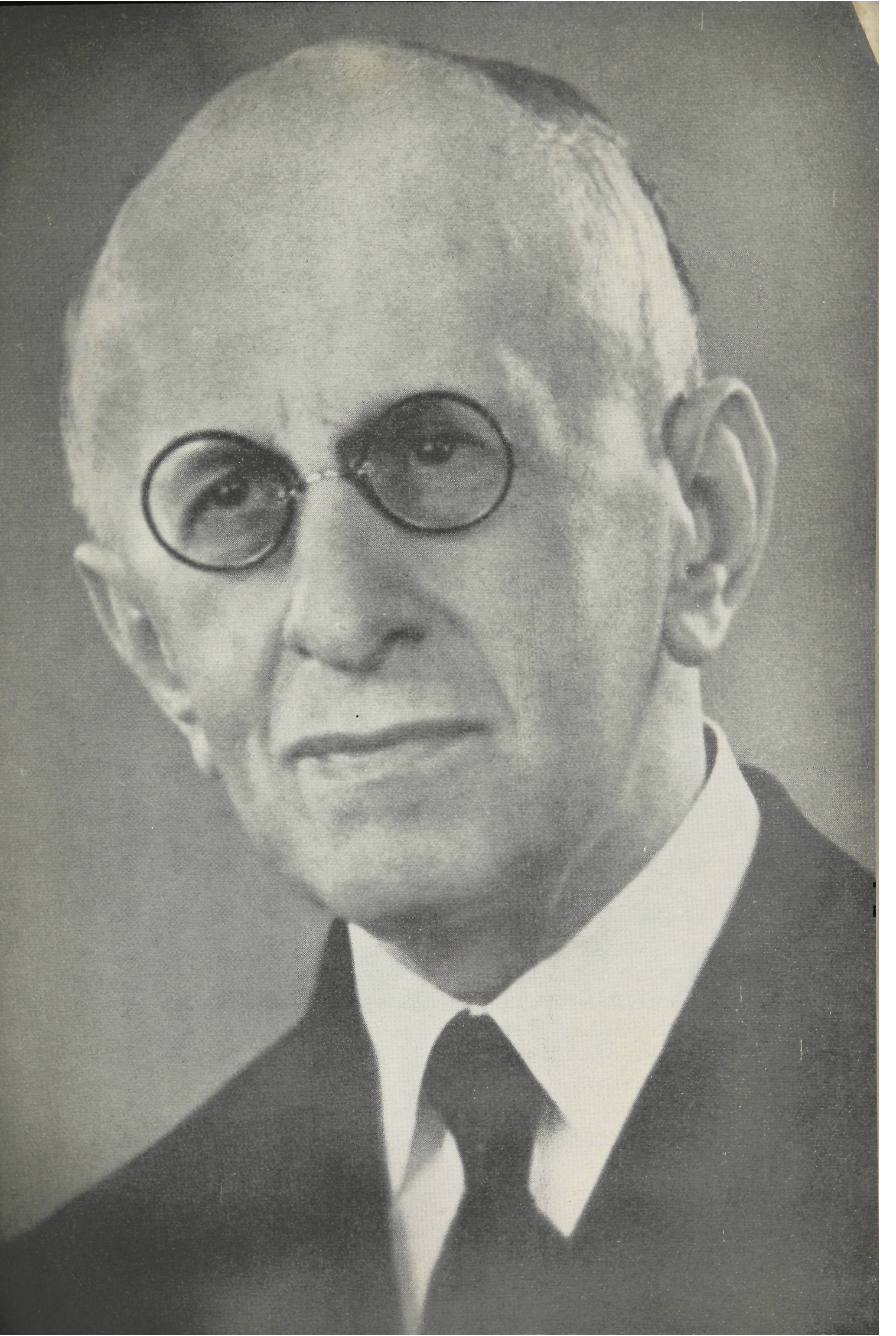




\section{Professor Emérito Reynaldo Porchat}

(1868-1953)

O falecimento do ilustre professor de Direito Romano, ocorrido a 12 de outubro de 1953, enlutou esta Faculdade, privando as letras juridicas do paiz de um de seus mais eminentes cultores. $O$ professor Porchat notabilisou-se sobretudo como romanista, deixando-nos o Curso Elementar de Direito Romano (1 volume, $2{ }^{a}$ edição, 1937, Cia. Melhoramentos de São Paulo), onde sintetisa com elegancia e rigor cientifico os frutos de toda uma vida consagrada ao ensino desta disciplina. Em seu livro, estudantes e juristas encontrarão sempre um manancial limpido de saber, baseado na familiaridade com as fontes e com a doutrina do Direito Romano, adquirindo, assim, os elementos indispensaveis de cultura juridica sólida, esclarecida e elevada.

o Curso Elementar de Direito Romano permanecerá em nossa literatura romanistica, quer pelo conteúdo, quer pela forma. Trata, de modo desenvolvido e profundo, primeiro da "Historia Externa", passando logo depois, a considerações de alto interesse sobre a "Importância do estudo. do Direito Romano e da sua expansão pela Europa", e sobre a "Influencia do Direito Romano na legislação civil patria" (capitulos I e II). O terceiro capitulo da "Introdução" é consagrado ao "Corpus Juris Civilis". Segue-se a "Parte Preliminar", cuidando da noção de direito, do direito subjetivo e objetivo, do direito publico e privado, das relações entre direito e moral. Exxaminam-se as noções romanas de justiça, equidade e jurisprudencia, as divisões: 
ne as fontes do direito. O estudo da Lei Civil é notavel sobretudo pelos capitulos relativos à doutrina da retroatividade da lei. Termina o livro pela "Parte Geral", onde - Autor estuda a noção de pessôa, (pessôa fisica, o nascituro, extinção da pessôa fisica), a capacidade juridica e a "capitis deminutio".

Não conseguiu o Professor Porchat executar o plano originário de Curso de Direito Romano, ficando, porisso, incompleta sua obra, devido aos múltiplos afazeres do advogado e a participação intensa na vida politica de São Paulo e do paiz. Com efeito, sua clientela era grande e importante; Porchat era jurista de gabinete e advogado militante, unindo a teoria à prática. Como politico, seu nome se liga indissoluvelmente ao Partido Democrático, de que foi um dos fundadores e cuja ação no cenário brasileiro foi das mais benéficas. A Universidade de São Paulo teve nele um de seus maiores reitores. Pertenceu, ainda, ao Conselho Nacional de Educação. Jurisconsulto por excelencia, orador eloquente, politico idealista, o Professor Porchat representa bem a mentalidade construtiva e patriótica dos varões ilustres de São Paulo. E, para os estudantes de hoje, ele é um exemplo conspicuo da força inspiradora que sempre emana dos estudos sérios de Direito Romano.

\section{A saudação da Academia}

A nossa Faculdade prestou ao eminente mestre as mais sentidas homenagens, tendo falado, antes da saida do féretro das Arcadas, o Prof. Cardoso de Melo Neto, interpretando o sentir de toda a Congregação. Foram as seguintes as palavras do Prof. Cardoso de Melo Neto: 
“A Congregação dos Professores da Faculdade de Direito de São Paulo despede-se do Professor Emerito Reynaldo Porchat.

E o faz num misto de comoção e orgulho.

De orgulho, porque todos nós seus discipulos, temos fixada, indelevel na memoria, aquela figura erecta e empolgante que, como de José Bonifácio, o moço, disse Ruy, quando assomava à catedra, no primeiro ano, "dava-nos a revelação viva da ciencia que abraçavamos". Porque ele não foi somente causidico, de larga clientela, mas um advogado, em toda a extensão do termo - culto, energico, argumentador de logica inteiriça, dono da mais preciosa qualidade do defensor do Direito, que é uma independencia.

Porque ele foi, durante a vida, na Academia e no Conselho Nacional de Educação o mais bravio, o mais eficiente, o mais autorizado e, porisso, o mais respeitado defensor da moralização do ensino no Brasil.

Porque, na politica, por onde passou como um meteoro, fez da cadeira do Senado uma tribuna de tal altitude, que se sentiu no dever de abandoná-la aos que o tinham eleito, entre o respeito dos adversarios, os aplausos do povo e a admiração da mocidade.

Porque, professor, ele conseguiu o milagre de ser, a um tempo, o mais temido por sua severidade e o mais amado por sua ação.

Por que o foi, se outros dentre a Congregação, existiam, por certo, de mais apurada ciencia, maiores juristas, tão patriotas e dignos como ele?

Porque tal como José Bonifacio, o moço, no Imperio, Porchat representou, na Republica, dentro da Academia, o ideal dos moços. 
Como o sobrinho e neto do Patriarca, ele foi um simbolo.

Ambos de uma eloquencia à Crispiniano, ambos politicos inconformados com as situações partidarias, ambos venceram a mocidade "não tanto porque sua palavra fosse um clarão, mas porque seu carater era uma claridade". (J. Serra).

Eis a razão pela qual, orgulhosa de seu filho dileto, aqui está, em despedida, a Faculdade de Direito de São Paulo.

Mestre e amigo, os filhos espirituais que creastes dentro. das Arcadas, e são todos quantos por ela passaram neste ultimo meio seculo, não mais ouvirão vossa voz inconfundivel. "Fala Porchat", era o nosso grito de guerra. Nunca mais falareis. Eis por que nos empolga a comoção".

\section{Outras homenagens}

Em nome do Conselho Nacional de Educação, do qual o prof. Reynaldo Porchat foi membro durante 37 anos, falou o prof. Almeida Junior, que historiou a atuação do falecido como educador e como intransigente defensor da legalidade e moralidade do ensino.

Em nome do Conselho Universitario e do reitor da Universidade, discursou o prof. Jaime Cavalcanti, que exalçou as virtudes do prof. Reynaldo Porchat, dizendo que era tal seu valor que, já em vida, recebia todas as mais meritorias distinções.

O prof. Noé Azevedo estudou a vida do extinto na sua qualidade de advogado, tendo falado em nome da Secção de São Paulo da Ordem dos Advogados do Brasil e, em nome do Instituto dos Advogados de São Paulo, discursou o sr. Paulo Bonilha, que enalteceu, especialmente as qualidades de coração do falecido. 


\section{O sepultamento}

Em seguida, precedido do estandarte da Faculdade de Direito e em carreta o esquife recoberto pelas bandeiras Nacional e Paulista foi conduzido para a necropole da Consolação, com grande acompanhamento de pessoas a pé.

Após a cerimonia da recomendação, ao descer o caixão À sepultura, falaram o prof. Soares de Melo, em nome da Academia Paulista de Letras; o estudante José Gregori e o sr. Francisco Sucupira.

\section{Dados bio-bibliográficos}

Nascido em Santos a 23 de Maio de 1868. Filho de Victoriano Porchat e de D. ${ }^{a}$ Prudência da Silva Porchat.

Aos sete anos de idade, veiu para São Paulo, tendo iniciado seus estudos no Colégio Ypiranga um ano após.

Aos 15 anos entrou para o comércio e trabalhou na casa Nothmann \& Cia. de Santos, de 1883 a 1884, quando voltou para São Paulo. Entrou para o Curso Anexo á Faculdade de Direito, para prosseguir seus estudos aqui, e depois no Rio de Janeiro no Mosteiro de São Bento. Foram seus professores no "Curso Anexo": Julio Ribeiro, Padre Chico, Galvão Bueno, João Kupre, Lapa Trancoso e outros.

No Mosteiro de São Bento, do Rio de Janeiro, travou conhecimento com o Dr. Milcíades de Sá Freire, com quem seguiu fraternalmente o curso jurídico, matriculando-se ambos na Faculdade de Direito de São Paulo em 1888.

Casou-se em 1890 (27 de dezembro), com D. ${ }^{a}$ Maria Julia Escobar de Lune.

Colou gráu de Bacharel em 26 de dezembro de 1891.

Havendo uma vaga de lente substituto na Faculdade de Direito, em 1897 entrou em concurso para a mesma, apresentando dissertação sôbre "Da Posição Jurídica dos Estados Federados Perante o Estado Flederal". - Aprovado 
unanimemente, foi nomeado para aquêle cargo por decreto de 18 de outubro de 1897, tomando posse a 23 do mesmo mès.

Os lentes que o aprovaram, foram: Cons. Leoncio de Carvalho, Brasílio dos Santos, João Monteiro, Vicente Mamede, Pedro Lessa, João Mendes Júnior, Oliveira Escorel, M. P. Vilaboim, Almeida Nogueira, Pinto Ferraz, CândidoMota, Alcantara Machado, Amancio de Carvalho, Ulpiano de Souza, Gabriel de Rezende e Veiga Filho.

Era então Diretor da Faculdade, e Presidente da Congregação, o Barão de Ramalho.

Foi promovido a Lente Catedrático de Direito Romano, por decreto de 20 de julho de 1903 , tomando posse do novo cargo a 27 do mesmo mês.

No período presidencial do Dr. Fernando Prestes, exerceu as funções de $10^{\circ}$ Delegado Auxiliar de Polícia, durante dois anos. Foi fiscal do Govêrno Federal junto ao Colégio de S. Luiz, dos Jesuitas, em Itú, nomeado pelo Dr. Epitácio Pessoa, Ministro da Justiça e Negócios Interiores da Republica, Eleito Senador Estadual em 1923 renunciou. ao mandato em 26 de dezembro de 1925.

Ém 1930 foi nomeado pelo Chefe do Govêrno Provisório, Dr. Getúlio Vargas, Diretor da Faculđade de Direito de São Paulo.

Quando estudante, foi professor de História Pátria, no Liceu de Artes e Ofícios de São Paulo, do qual chegou a ser Presidente, e depois Presidente Honorário, foi um dos. fundadores do Partido Democrático.

Foi nomeado membro do Tribunal Regional de Justiça Eleitoral, por ter sido um dos advogados indicados pelo Tribunal de Justiça de São Paulo, e ai serviu como Juiz por mais de dois anos, tendo deixado o cargo quando foi nomeado, em 1934, pelo Interventor Federal, Dr. Armando. de Salles Oliveira, Reitor da Universidade de São Paulo, então recentemente fundada. 
Era o membro mais antigo do Conselho Nacional de Educação, desde sua fundação em 1911, quando se denominava Conselho Supierior de Ensino, tendo sido unânimemente eleito pela Congregação da Faculdade de Direito de São Paulo, e exercido a Presidência do Conselho durante varias gestões, em virtude de sucessivas reeleições também unânimes. Teve de afastar-se, ultimamente, do Conselho por motivo de sua já precária saúde.

Foi membro do Comité correspondente do "Groupment des Universités et Grandes Ecoles de France", que fundou em São Paulo o Liceu Franco Brasileiro, tendo sido também membro do "Comité France-Amerique" e da Sociedade Geográfica de Lisboa.

Escreveu o "Curso Elementar de Direito Romano", ha muito esgotado, além da monografia sôbre a "Retroatividade, das Leis Civis". Ưm volume sôbre "A Pessoa Física em Direito Romano", e os "Vários Discursos" além de numerosos artigos e pareceres sôbre assuntos jurídicos.

Pertenceu ao Clube Republicano Acadêmico, quando estudante, e foi um dos redatores do periódico político acađêmico "A República”.

Foi incluido pelo Supremo Tribunal Federal, na lista apresentada do Govêrno Provisório, Dr. Getúlio Vargas, para Ministro dêsse Tribunal. 